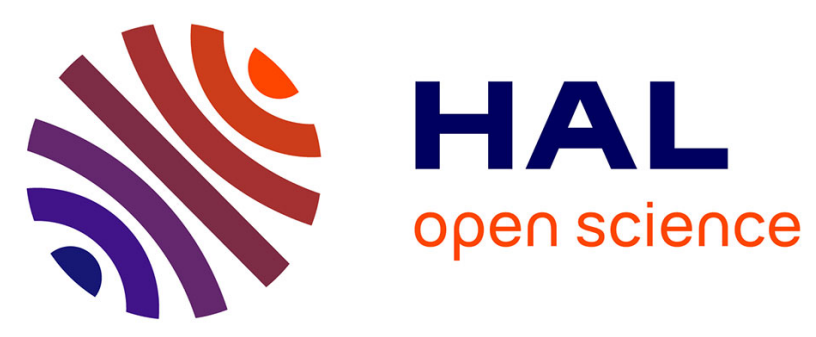

\title{
High current density production of multicharged ions with ECR plasma heated by gyrotron transmitter
}

\author{
J.L. Bouly, J.C. Curdy, R. Geller, S.V. Golubev, A. Lacoste, T. Lamy, P. Sole,
} P. Sortais, S.V. Razin, J.L. Vieux-Rochaz, et al.

\section{- To cite this version:}

J.L. Bouly, J.C. Curdy, R. Geller, S.V. Golubev, A. Lacoste, et al.. High current density production of multicharged ions with ECR plasma heated by gyrotron transmitter. International Conference on Ion Sources 9, 2001, Oakland, United States. pp.528-530, 10.1063/1.1430030 . in2p3-00011240

\section{HAL Id: in2p3-00011240 \\ https://hal.in2p3.fr/in2p3-00011240}

Submitted on 24 Nov 2020

HAL is a multi-disciplinary open access archive for the deposit and dissemination of scientific research documents, whether they are published or not. The documents may come from teaching and research institutions in France or abroad, or from public or private research centers.
L'archive ouverte pluridisciplinaire HAL, est destinée au dépôt et à la diffusion de documents scientifiques de niveau recherche, publiés ou non, émanant des établissements d'enseignement et de recherche français ou étrangers, des laboratoires publics ou privés.

\section{(c)(1)}

Distributed under a Creative Commons Attribution| 4.0 International License 


\title{
High current density production of multicharged ions with ECR plasma heated by gyrotron transmitter
}

\author{
J. L. Bouly, J. C. Curdy, and R. Geller \\ Institut des Sciences Nucléaires UJF-IN2P3-CNRS, 53 Av. des Martyrs, 38026 Grenoble Cedex, France
}

S. V. Golubev

Institute of Applied Physics of Russian Academy of Sciences, 603600, Ulyanov Str. 46, Nizhny Novgorod, Russia

A. Lacoste, T. Lamy, P. Sole, and P. Sortais

Institut des Sciences Nucléaires UJF-IN2P3-CNRS, 53 Av. des Martyrs, 38026 Grenoble Cedex, France

S. V. Razin

Institute of Applied Physics of Russian Academy of Sciences, 603600, Ulyanov Str. 46, Nizhny Novgorod, Russia

J. L. Vieux-Rochaz and T. Thuillier

Institut des Sciences Nucléaires UJF-IN2P3-CNRS, 53 Av. des Martyrs, 38026 Grenoble Cedex, France

A. V. Vodopyanov and V. G. Zorin

Institute of Applied Physics of Russian Academy of Sciences, 603600, Ulyanov Str. 46, Nizhnyn Novgorod, Russia

In order to study the possibilities to produce high currents of pulsed heavy ion beams dedicated to synchrotron injection, two new approaches of ECR devices are now underway. The basic principle consists in maintaining a functioning point of the source with the highest density as possible and a minimum confinement time for the production of a given charge state. It means that for a constant $n_{e} \tau_{i}$ product we try to maximize $n_{e}$ and minimize $\tau_{i}$. For this purpose two experiments are in progress at ISN/Grenoble ${ }^{\mathrm{a}}$ and IAP/Nizhny Novgorod. ${ }^{\mathrm{b}}$ The first one consists of using a minimum $|B|$ magnetic structure with a 1.8 mirror ratio characteristic value with a $28 \mathrm{GHz}$ frequency injection. In this case we explore different functioning points up to $10 \mathrm{~kW}$ of UHF power. The second one consists of a simple mirror magnetic system (simple mirror ion source, SMIS) working at $37.5 \mathrm{GHz}$ with a mirror ratio up to $3(2.5 \mathrm{~T})$ where we study discharges with a peak power up to $100 \mathrm{~kW}$. We will show that, in spite of a very short rising time of the current, we can maintain the production of multicharged ions and that we can observe very high current densities. In the future, the challenge will be the design of an extraction geometry matching theses current levels.

\section{INTRODUCTION}

The two main parameters that measure the capability of a plasma to produce multicharged ion are the electronic density $n_{e}$ and the confinement time of the ions $\tau_{i}$ especially if we assume that the suitable electronic energy can be achieved in any case due to the efficiency of the ECR heating.

The product $n_{e} \tau_{i}$ is a rough measurement of the collision rate so it is roughly proportional to the $\langle Z\rangle$ of the ion in the plasma. The ratio $n_{e} / \tau_{i}$ is roughly proportional to the flux of particles arriving to the wall so the current density of a given charge state.

The aim of this project consists in multiplying the density by a factor of 3 , that seems achievable with a $28 \mathrm{GHz}$ discharge and optimizing the confinement time with a divi-

${ }^{a}$ Under grant CERN/GSI/CEA/IN2P3 K598/PS and EU Contract No. HPRI1999-50019.

${ }^{\mathrm{b}}$ Under Grant IAP/IN2P3-2/2001. sion by a factor of 3 . In this case the $n_{e} \tau_{i}$ product remains constant and only the ratio $n_{e} / \tau_{i}$ is multiplied by a factor of 10. The current is multiplied by a factor of 10 and the $\langle Z\rangle$ remains constant so we look for a modification of the charge state distribution as illustrated by Fig. 1. We think that this functioning point could be achieved in a quite simple 28 $\mathrm{GHz}$ classical source working with a mirror ratio around 1.5. Finally, if we plan to work with high density and low confinement it means that the loss rate of the particles will be very high so that will need of a strong UHF power density in order to maintain the electronic density.

\section{PHOENIX $28 \mathrm{GHz}$}

\section{A. General layout}

The purpose of this project consists of using a very high density plasma in a quite medium confinement device in order to generate very high current density beams for the generation of high currents. 


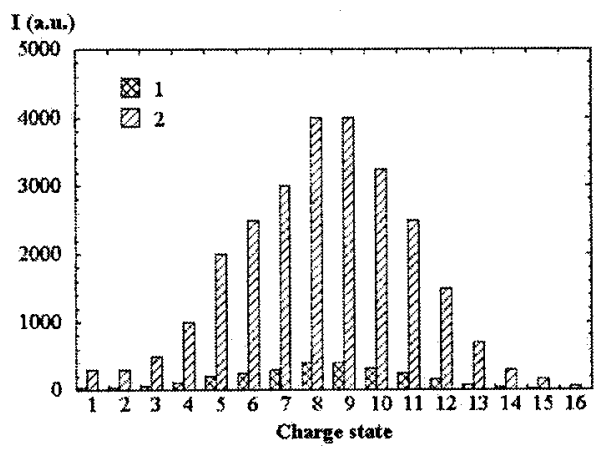

FIG. 1. Low flux and high flux charge state distribution with constant $\langle Z\rangle$.

It is the reason why PHOENIX is a compact machine matched to a $10 \mathrm{~kW}, 28 \mathrm{GHz}$ gyrotron. The plasma chamber is a $74 \mathrm{~mm}$ in diameter and $300 \mathrm{~mm}$ in length tube with a direct and axial injection of the wave. The waveguide is a TE01 oversized for the $28 \mathrm{GHz}$ frequency and it has a diameter of $32 \mathrm{~mm}$ (Fig. 2).

An important point is the introduction of a thick insulator $(3 \mathrm{~mm})$ between the coils and the inner part of the source in order to achieve an insulation up to $60 \mathrm{kV}$ for the extraction of high current density. The axial magnetic profile is just matched to a $28 \mathrm{GHz}$ ECR frequency for a mirror ratio of roughly 1.5 . In this case the maximum axial field is $1.6 \mathrm{~T}$ at the injection of the wave and $1.4 \mathrm{~T}$ at the extraction for a 1300 A current inside the coils. The electrical consumption is roughly $200 \mathrm{kVA}$ in this case. The radial field is done with a classical $80 \mathrm{~mm}$ in diameter FeNdB hexapole delivering 1.5 $\mathrm{T}$ on the pole.

\section{B. High current density measurements}

In a first step we only try to identify the possibility of production of very high current densities (above 20 $\mathrm{mAe} / \mathrm{cm}^{2}$ ). We have started the source at the present maximum extraction voltage of $48 \mathrm{kV}$ and with a $2 \mathrm{~mm}$ extraction. We have easily extracted $4 \mathrm{mAe}$ of total current with nitrogen corresponding to $3 \mathrm{mAe}$ of total current arriving on the Faraday cup (75\% of transmission and $0.9 \mathrm{mAe}$ of $\mathrm{N}^{3+}$; Fig. 3). In this case it means that we can reach a density close to $100 \mathrm{mAe} / \mathrm{cm}^{2}$ at least in a $2 \mathrm{~mm}$ hole.

In this case we have switched the extraction hole to 6 $\mathrm{mm}$ (gap $35 \mathrm{~mm}$ ) and study the production and transmission at $45 \mathrm{kV}$ (Fig. 4). We can see the currents delivered by the high voltage power supply, measured in a Faraday cup placed just at the exit of the puller, the sum of all the ionic

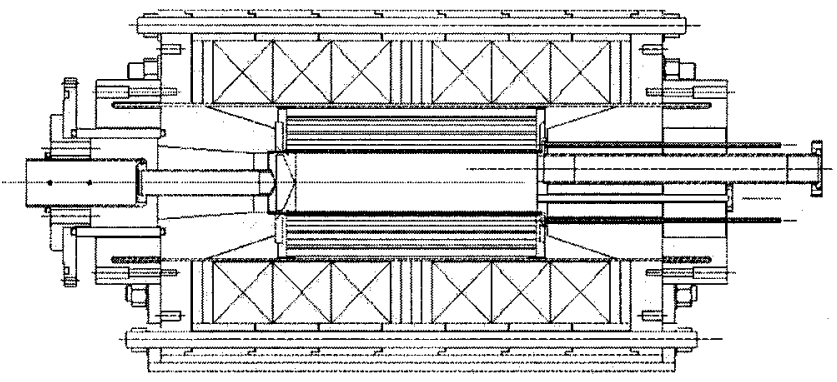

FIG. 2. The source PHOENIX $28 \mathrm{GHz}$.

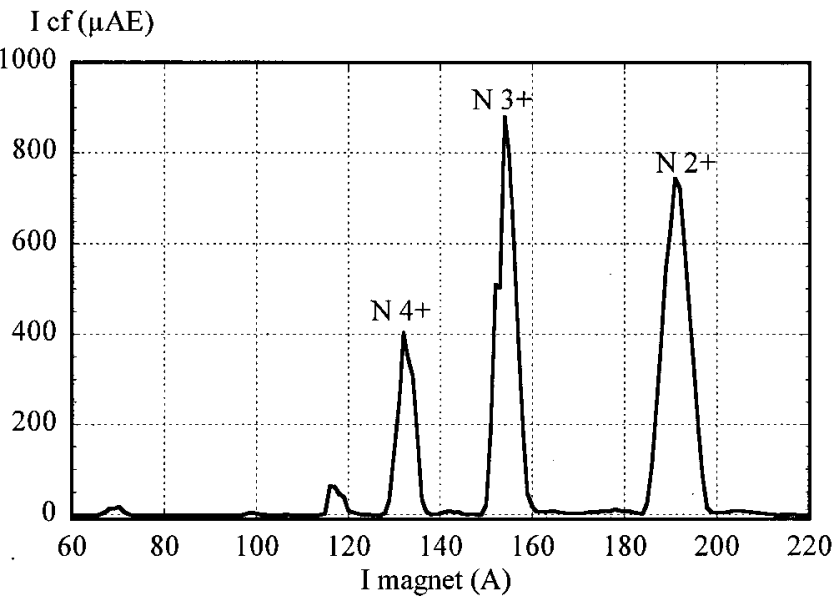

FIG. 3. $\mathrm{N}^{3+}$ up to $900 \mu \mathrm{A}$ with $\varnothing 2 \mathrm{~mm}$ extraction hole at $48 \mathrm{kV}$.

currents arriving in the Faraday cup placed after the bending magnet and the current of $0^{4+}$ as a function of the UHF power.

We can see that at a low extracted current of $3.5 \mathrm{mAe}$ after the puller $\left(12 \mathrm{mAe} / \mathrm{cm}^{2}\right)$ we have a very good transmission. All the drain current arrive at the exit of the puller and are transferred through the bending magnet. But around 6 mAe after the puller $\left(21 \mathrm{mAe} / \mathrm{cm}^{2}\right)$ we observe a saturation of the current after the bending magnet $(4.4 \mathrm{mAe})$ indicating a clear space charge limitation through the beam line. Now around $7 \mathrm{mAe}$ after the puller we began to see a major difference between the drain current and the Faraday cup current indicating the beginning of current losses and generation of the secondary electrons directly on the puller. Now it is the extraction gap that is space charge limited.

The conclusion of the present experiments are that we can easily produce high current densities of multicharged ion

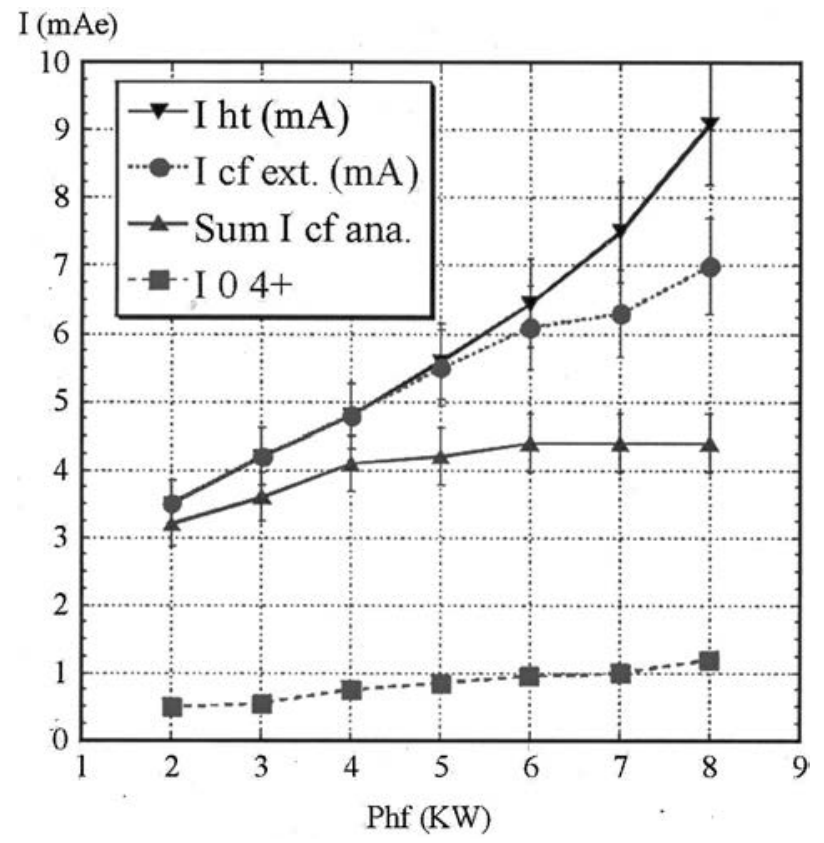

FIG. 4. Power dependence of the drain current $\left(I_{h t}\right)$, the Faraday cup current at the exit of the puller $\left(I_{\text {cf ext. }}\right)$ and the total current of the spectrum at the exit of the bending magnet $\left(\Sigma I_{\text {cf ana. }}\right)$. 


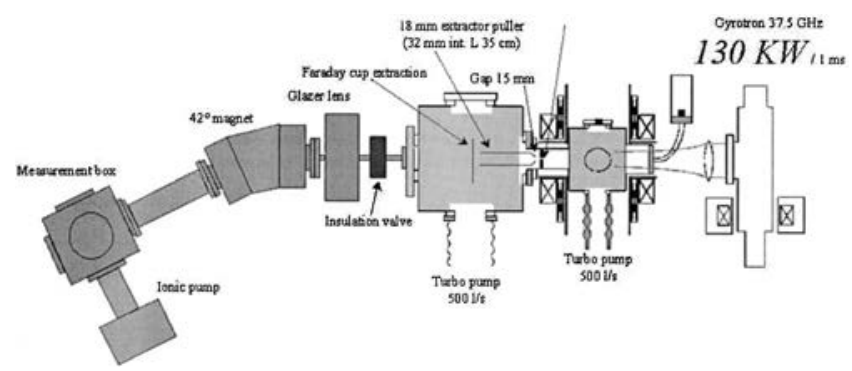

FIG. 5. SMIS $37.5 \mathrm{GHz}$ experimental setup.

but we have to match the extraction voltage to each value in order to get a good transmission. In a near future an upgrade of the voltage and the acceptance of the beam line will be done.

\section{SMIS $37 \mathrm{GHz}$}

\section{A. General layout}

In parallel with the PHOENIX experiment a second device developed at the IAP of Nizhny Novgorod (Russia) and called simple mirror ion source $37.5 \mathrm{GHz}$ is used to study the production of very high current density of multicharged ions.

Here a new step in the reduction of the confinement is done. The source is reduced to a simple axial magnetic mirror placed around a simple stainless steel plasma chamber ${ }^{1}$ (Fig. 5). There is no hexapole and the pulsed UHF power is injected on the axis of the source through a glass window. In this case the extraction hole is reduced to $1 \mathrm{~mm}$ only. Due to technological limitations the magnetic field is pulsed and has a maximum value of $2.5 \mathrm{~T}$ during roughly $10 \mathrm{~ms}$. The pulsed duration of the UHF power is limited by the high voltage power supply and has a maximum duration of $1 \mathrm{~ms}$ with a peak power of $130 \mathrm{~kW}$. Another specificity of this device is the use of a quasi-optical coupling for the UHF injection. The power extracted from the gyrotron is a Gaussian beam that is refocused by a dielectric lens before the injection under vacuum through the glass window of the source. In this case there is no physical connection between the transmitter and the source, so there is no problem of insulation and power density transmission.

The source can presently be biased only up to $15 \mathrm{kV}$ and the analyze of the beam is done with the former charge breeding beam line of ISN/Grenoble that has been transferred to Nizhny Novgorod.

\section{B. Preliminary result}

We can see in Fig. 6 a first result obtained for nitrogen (with $\mathrm{C}$ from outgassing). Here we show the spectrum during the $1 \mathrm{~ms}$ pulse of the UHF power and at five steps of $200 \mu \mathrm{s}$. We see that a full spectrum of multicharged ions of nitrogen can be produced in an opened trap. Here we have a clear illustration of the compensation of the reduction of the confinement time by a very strong power density used to maintain the electronic density. The peak power is $60 \mathrm{~kW}$ for a 1

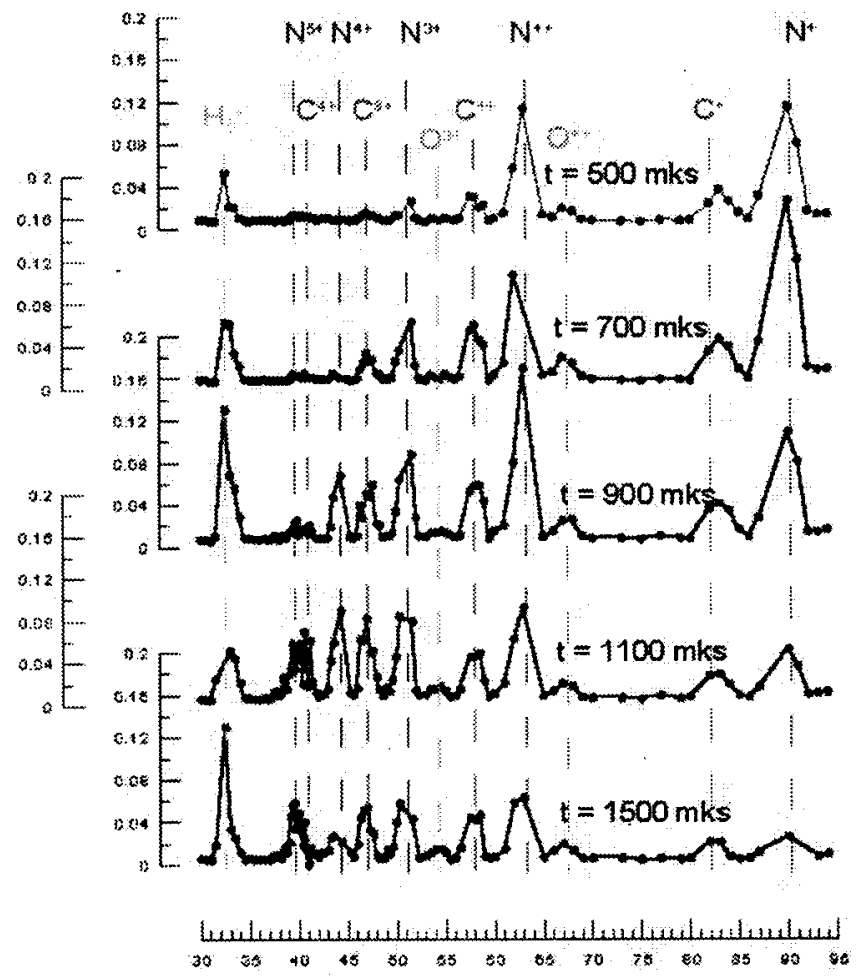

FIG. 6. Charge state distribution of N obtained with SMIS and with $200 \mu \mathrm{s}$ steps.

1 plasma chamber and the rising time of the current of $\mathrm{N}^{4+}$ or $\mathrm{N}^{5+}$ is only some hundreds of $\mu \mathrm{s}$. In this case the total current extract from the source is around $5 \mathrm{mAe}$ with roughly $3 \mathrm{mAe}$ measured at the level of the extraction Faraday cup. The current density reaches more than 400 $\mathrm{mAe} / \mathrm{cm}^{2}$ that is roughly 10 times more than with PHOENIX and 100 times than a classical source. Of course, the transmission is very poor because of the low extraction voltage and the poor acceptance of the beam line. This aspect will be upgraded in a near future but the purpose of this first experiment consists in showing the possibility to produce multicharged ions inside a ion source without radial magnetic field.

\section{CONCLUSION}

We start new compact devices working with high frequency and high power density and we clearly observe a drastic increase of the current density of multicharged ions. These currents densities can be produced in a minimum $|B|$ structure with a power density in the range of $5 \mathrm{~kW}$ per liter or in an open magnetic trap with a power density in the range of $50 \mathrm{~kW}$ per liter. The next step is now the control of the beam formation in the characteristic environment of an ECR ion source for the production of multi-milliamperes multicharged ion beams. ${ }^{1}$ V. G. Zorin, S. V. Golubev, and S. V. Razin, Rev. Sci. Instrum. 69, 634
(1998). 